\title{
BACTERIAL SPECTRUM AND ANTIMICROBIAL PATTERN OF BLOOD STREAM INFECTIONS ASSOCIATED WITH NON-TUNNELED DOUBLE LUMEN CATHETER IN HEMODIALYSIS PATIENTS
}

\author{
Mehmood Hussain, Malik Nadeem Azam Khan, Khalid Rehman*, Irfan Ali Mirza**, Maryam Rehman, Sidra Riaz \\ Pak Emirates Military Hospital/National University of Medical Sciences (NUMS) Rawalpindi Pakistan, *Combined Military Hospital Multan/National University \\ of Medical Sciences (NUMS) Pakistan, **Armed Forces Institute of Pathology/National University of Medical Sciences (NUMS) Rawalpindi Pakistan
}

\section{ABSTRACT}

Objective: To assess Bacterial spectrum and antimicrobial pattern of Blood Stream Infections associated with non-tunneled double lumen catheter in hemodialysis patients.

Study Design: Prospective observational study.

Place and Duration of Study: Department of Nephrology, Pakistan Emirates Military Hospital Rawalpindi Pakistan; Armed Forces Institute of Pathology Rawalpindi, Pakistan, from May 2019 to Apr 2020.

Methodology: A total of 753 patients underwent placement of non-tunneled double lumen catheter (457 femoral, 296 Internal Jugular). Patients with clinically suspected bloodstream infections had their catheters removed with tips being sent for culture along with 2 sets of peripheral blood cultures. Patients were labelled as having bloodstream infection if growth of organism was detected in catheter tip and at least one peripheral blood culture. Susceptibility testing was done for available antimicrobials.

Results: One hundred and thirty six (18.06\%) incidences or 5.48 bloodstream infections per 1000 catheter days, with confirmed growth on blood cultures were identified. Gram positive infections were seen in $76(55.88 \%)$ individuals with most common organism being coagulase-negative Staphylococcus (28.68\%), followed by Staphylococcus aureus (21.32\%). These organisms had low resistance rates to Vancomycin (0\%), Tigecycline (0\%), Doxycycline $(6.6 \%)$ and Linezolid $(9.5 \%)$. Gram negative infections were seen in $60(44.11 \%)$ patients with Klebsiella pneumoniae $(13.24 \%)$ being the most commonly identified pathogen followed by Acinetobacter baumannii (12.50\%) and had relatively higher degree of antimicrobial resistance.

Conclusion: Gram positive organisms were the most common cause of bloodstream infection in this study and were found susceptible to vancomycin and doxycycline whereas gram-negative organisms had high rates of antimicrobial resistance.

Keywords: Blood stream infection, Coagulase negative staphylococcus, Double lumen catheter, Hemodialysis.

This is an Open Access article distributed under the terms of the Creative Commons Attribution License (https://creativecommons.org/licenses/by-nc/4.0/), which permits unrestricted use, distribution, and reproduction in any medium, provided the original work is properly cited.

\section{INTRODUCTION}

Catheter related blood stream infections (CRBSI) can be defined as "positive culture of the catheter (on removal), or paired blood cultures from a peripheral vein and the catheter (when left in place) with isolation of identical organisms (both species and antibiograms) from cultures of catheter segments and blood drawn from a peripheral vein in a patient with clinical symptoms of sepsis and the absence of another source of infection"1. Non-tunneled hemodialysis catheter is a fast and easily accessible method to initiate dialysis in most patients. United States Renal Data System reveals that as many as $80.1 \%$ of individuals start hemodialysis via central catheter and up to $35 \%$ continue dialysis via central catheter beyond 12 months². Even though catheter access has some benefits, a high rate of complications makes it a less preferred option. CRBSI in this subset of population is both common and feared complication as it leads to increased morbidity and morta-

Correspondence: Dr Mehmood Hussain, House No, 80, Sarwar Lane, Near Heart International Hospital, Rawalpindi Pakistan

Received: 09 Jun 2020; revised received: 30 Jul 2021; accepted: 13 Aug 2021 lity $^{3}$. It can result in life threatening complications including septic shock, endocarditis, lung abscess, osteomyelitis or septic arthritis ${ }^{3,4}$. In a study conducted in Pakistan, prevalence of hemodialysis catheter colonization was seen in $51.6 \%$ individuals and bacteremia in $25 \%{ }^{5}$. Worldwide incidence of dialysis related CRBSI is between 2.5-5-5 cases per 1,000 catheter days, or 0.9-2.0 episodes per patient year' ${ }^{6}$.

Due to this high prevalence, bacteremia is the second most common cause of mortality after cardiovascular disease in Chronic Kidney Disease (CKD) in US7, and most common cause in CKD patients undergoing dialysis via dialysis catheter in some studies 8 . Previous studies have shown gram positive cocci especially skin colonizers such as coagulase negative Staphylococci and $S$. aureus to be the most commonly involved pathogens $\mathrm{s}^{6,9}$. Other common organisms include Gram negative rods (GNRs) and Enterococci6,9. As these patients commonly receive broad spectrum antibiotics empirically, antibiotic resistance is common. It is therefore, necessary to recognize the local microbiology and susceptibility pattern to provide effective empiric ther- 
apy in order to decrease both mortality and emergence of antimicrobial resistance. This study was directed to learn incidence, bacteriological spectrum and microbiological characteristics of BSI in local population.

\section{METHODOLOGY}

This prospective observational study was conducted at the department of Nephrology of Pak Emirates Military Hospital and Armed Forces Institute of Pathology, Rawalpindi Pakistan, from May 2019 to April 2020 after approval from Ethics Review Board of same hospital via letter no Ex/FC-18/READ-IRB/19/406. Using a previously reported prevalence of $25 \%$ of catheter related bacteremia in our population and estimated 5\% margin of error with $99 \%$ confidence interval, an estimated sample size of 498 was calculated using WHO sample size calculator ${ }^{5}$.

Patients included in study were undergoing dialysis via non-tunneled hemodialysis catheter and between ages of 18-80 years. Patients who were undergoing hemodialysis via either tunneled catheter or AV Fistula or had established septicemia were excluded. Non-probability consecutive sampling technique was utilized and informed consent was taken. If a patient required more than one catheter during observational period then each catheter insertion was taken as a separate incidence. A total of 753 incidences of catheter insertion were included in the analysis. Catheters were inserted by a physician with strict antiseptic measures using Seldinger's technique under ultrasound guidance in either Femoral Vein or Internal Jugular Vein (IJV) and sutured to skin. Insertion point was then covered by sterile occlusive dressing which was changed on each dialysis session or sooner if contaminated. During each dialysis session, entry site of catheter was seen for any presence of local inflammation and purulent discharge by trained nursing staff.

Catheters were removed if they were no longer needed, blocked, or in case of any local or systemic complication. Duration of catheter placement was noted. Patients were observed for signs of local or systemic infections. In patients who had signs of local or systemic infections that included fever with chills, pain or purulent discharge, early signs of sepsis (tachycardia, hypotension or altered mental state), systemic involvement (Endocarditis, Thrombophlebitis, Septic Arthritis or Abscess) or raised inflammatory markers (TLC, CRP, Procalcitonin), their dialysis catheter was removed and distal 3-5 $\mathrm{cm}$ tip along with two samples from peripheral vein were taken for culture as per Clinical and Laboratory Standards Institute (CLSI) guidelines ${ }^{10}$. CRBSI was defined as growth of same organism from at least 1 percutaneous blood culture and from a culture of catheter tip as per Infection disease society of America (IDSA) guidelines ${ }^{11}$. All pathogens recovered from cultures were identified by standard microbiological procedure and susceptibility testing was done for available antibiotics.

All data was initially recorded in written form and was later transferred to Microsoft Excel 2016. Statistical analysis was done using Microsoft Excel 2016. Continuous variables such as age were expressed as age \pm SD. Categorical variables were expressed as relative or absolute frequencies and percentages.

\section{RESULTS}

A total of 753 individuals were included in the study with mean age of $57.06 \pm 11.82$ years. Males constituted 501 (66.53\%) while females were 252 (33.47\%) of study population. Common risk factors in this group included hypertension $(79.81 \%)$, diabetes $(42.9 \%)$, cardiovascular diseases $(24.83 \%)$, autoimmune disease (18.86\%) and liver disease (15\%). Among 407 (54.05\%) catheters were femoral and $346(45.95 \%)$ were placed in IJV with average catheter time across population was 32.95 days. Among 753 individuals, 228 (30.28\%) patients showed one or more symptom or sign of bloodstream infection (BSI) and hence their catheter tips along with peripheral blood samples were sent for culture and sensitivity. Common symptoms in this subgroup were fever $(88.60 \%)$, chills $(65.78 \%)$, local inflammation $(38.16 \%)$, pus discharge from catheter site $(12.28 \%)$, septic shock $(8.77 \%)$ and misc systemic complication $(9.65 \%)$ including Septic Arthritis, abscess and pneumonia.

Among 228 patients, definite evidence of CRBSI as per IDSA criteria was seen in 136 patients (18.06\%). Average age in this subset was $57.88 \pm 12.78$ years with $86(63.24 \%)$ being males and females accounting for 50 $(36.76 \%)$ of the cases. Femoral catheters had a higher risk of causing CRBSI (100 out of 407 or $24.5 \%$ ) as compared to IJV catheters (36 out of 346 or $10.40 \%$ ) with relative risk of 2.36. Average time to infection after catheter insertion was $21.66 \pm 7.27$ days with shorter time to infection seen in femoral catheters $(20.11 \pm 6.91$ days) compared to IJV catheters (25.97 \pm 6.56 days). This translates to about 5.48 incidences of CRBSI per 1000 catheter days overall (Infection per 1000 days $=$ Total incidences of CRBSI/Total Catheter days x 1000). Rate of infection per week are shown in fig-1A.

In this study $55.88 \%$ of CRBSI were caused by gram positive organisms coagulase negative Staphylo- 
cocci being the most common causing $28.68 \%$ of infections, followed by Staphylococcus aureus and Klebsiella pneumoniae at $21.32 \%$ and $13.24 \%$ respectively. Detailed distribution of organisms is shown in fig-1B.

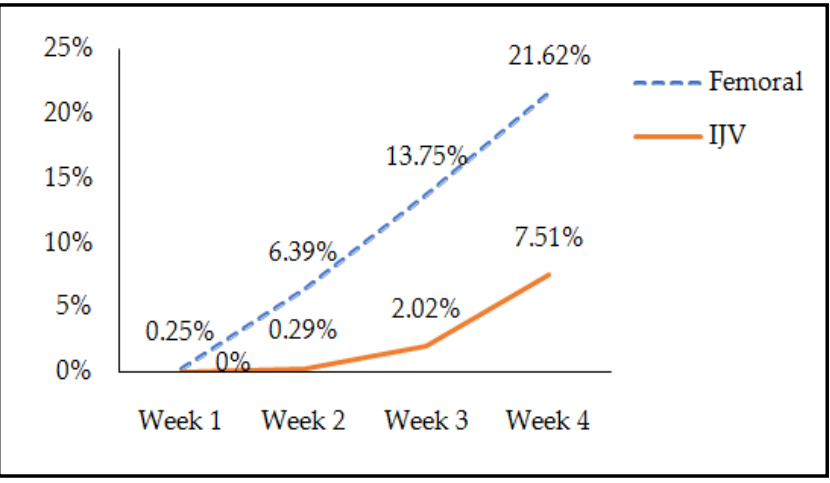

Figure-1A: Weekly rate of infection.

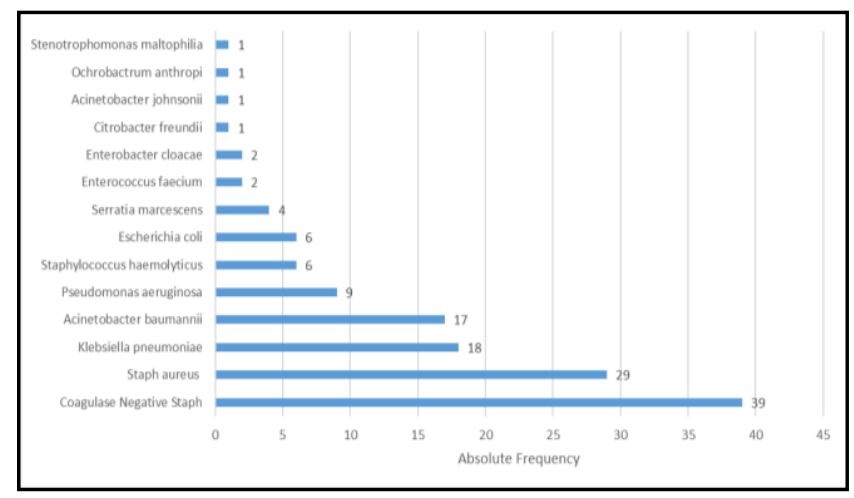

Figure-1B: Absolute frequency of organisms causing CRBSI.
Susceptibility patterns of the isolated gram positive and negative pathogens has been shown in table-I \& II respectively. All gram-positive pathogens were susceptible to vancomycin and tigecycline and had low rates of resistance to doxycycline and linezolid. Among S. aureus, $58.6 \%$ were methicillin-resistant. Gram negative organisms had high rates of resistance to ampicillin, ceftriaxone and ciprofloxacin $(94.23 \%, 96.77 \%$ \& $74 \%$ respectively) (table-III). Co-morbidities associated with CRBSI in this population with Relative Risk are described in table-IV.

\section{DISCUSSION}

Temporary non-tunneled catheters, unlike other modalities (Tunneled Double Lumen, AV Fistula, AV Graft) provide a rapid access for hemodialysis in acute kidney injury (AKI) acute on chronic kidney disease (CKD) and when emergency dialysis is required ${ }^{2}$. In US, CRBSI form third commonest cause of hospital acquired infections with an attributable mortality rate of $12-25 \%^{2}$. Each incident of infection can cost an average of $\$ 20,000$ to $\$ 25,000$ US dollars ${ }^{12}$.

In this study, hypertension, diabetes and cardiovascular disease were the most common underlying comorbidities in patients undergoing hemodialysis. These comorbidities were even more common in subset of patients developing CRBSI with especially high relative risk for diabetes, autoimmune disease and hypertension. Similar findings were reported by Allon et $a l^{3}$, and Nasser et al 9 .

International Nosocomial Infection Control Con-

Table-I: Antibiotic resistant rates among gram positive pathogens from study population.

\begin{tabular}{l|c|c|c|c}
\hline $\begin{array}{l}\text { Antimicrobial } \\
\text { Drug }\end{array}$ & $\begin{array}{c}\text { Coagulase Negative } \\
\text { Staphylococci (n=39) }\end{array}$ & $\begin{array}{c}\text { Staphylococcus } \\
\text { Aureus (n=29) }\end{array}$ & $\begin{array}{c}\text { Staphylococcus } \\
\text { Haemolyticus (n=6) }\end{array}$ & $\begin{array}{c}\text { Enterococcus } \\
\text { Faecium (n=2) }\end{array}$ \\
\hline Penicillin & 91.9 & 96.6 & 100 & 100 \\
\hline Ampicillin & 91.9 & 95.8 & 100 & 100 \\
\hline Co-Amoxiclav & 84.2 & 78.6 & 83.3 & 100 \\
\hline Cloxacillin & 61.1 & 58.6 & 100 & 100 \\
\hline Piperacillin-Tazobactam & 56.4 & 58.6 & 100 & 100 \\
\hline Cephradine & 80.8 & 72 & 100 & 100 \\
\hline Cefepime & 33.3 & 16.7 & 0 & - \\
\hline Vancomycin & - & - & 16.67 & - \\
\hline Linezolid & 10.3 & 6.9 & - & - \\
\hline Tigecycline & - & - & 66.7 & 100 \\
\hline Co-Trimoxazole & 65.7 & 25.9 & 100 & 100 \\
\hline Erythromycin & 85.7 & 86.2 & 50 & 100 \\
\hline Clindamycin & 48.7 & 40.7 & - & 50 \\
\hline Doxycycline & 7.7 & 3.6 & 66.7 & Not Done \\
\hline Gentamicin & 69.7 & 61.5 & 33.3 & Not Done \\
\hline Amikacin & 13.9 & 30.8 & 83.3 & 100 \\
\hline Ciprofloxacin & 75 & 79.2 & 75 & Not Done \\
\hline Fusidic Acid & 83.3 & 50 & & \\
\hline
\end{tabular}


sortium surveillance data reported a CRBSI rate of 4.1 per 1000 catheter days 13 while in this sample CRBSI was seen in 5.48 cases per 1000 catheter days which was within the described range available in previous studies (table-IV). Most common isolated organisms sitivity but low specificity as other infective etiologies may present with similar features $3,20,21$.

In our population high rates of antimicrobial resistance were seen in both gram positive and negative organisms. In gram positive organisms $61.1 \%$ of coa-

Table-II: Antibiotic resistant rates among gram negative pathogens from study population.

\begin{tabular}{|c|c|c|c|c|c|c|c|c|c|}
\hline $\begin{array}{l}\text { Antimicrobial } \\
\text { Drug }\end{array}$ & \multicolumn{2}{|c|}{$\begin{array}{c}\text { Klebsiella } \\
\text { Pneumoniae }(n=18)\end{array}$} & \multicolumn{2}{|c|}{$\begin{array}{c}\text { Acinetobacter } \\
\text { Baumanii }(n=17)\end{array}$} & \multicolumn{2}{|c|}{$\begin{array}{l}\text { Pseudomonas } \\
\text { Aeruginosa }(n=9)\end{array}$} & \multicolumn{2}{|c|}{$\begin{array}{c}\text { Escherichia } \\
\text { Coli }(n=6)\end{array}$} & $\begin{array}{c}\text { Serratia } \\
\text { Marcescens }(n=4)\end{array}$ \\
\hline Penicillin & \multicolumn{2}{|c|}{100} & \multicolumn{2}{|c|}{100} & \multicolumn{2}{|c|}{100} & \multicolumn{2}{|c|}{100} & 100 \\
\hline Ampicillin & \multicolumn{2}{|r|}{100} & \multicolumn{2}{|r|}{100} & \multicolumn{2}{|c|}{100} & \multicolumn{2}{|r|}{100} & 100 \\
\hline $\begin{array}{l}\text { Piperacillin- } \\
\text { Tazobactam }\end{array}$ & \multicolumn{2}{|r|}{33.33} & \multicolumn{2}{|r|}{71.4} & \multicolumn{2}{|c|}{22.2} & \multicolumn{2}{|r|}{25} & 25 \\
\hline Ceftriaxone & \multicolumn{2}{|r|}{83.3} & \multicolumn{2}{|r|}{100} & \multicolumn{2}{|c|}{100} & \multicolumn{2}{|r|}{100} & 66.7 \\
\hline Sulzone & \multicolumn{2}{|r|}{66.7} & \multicolumn{2}{|r|}{85.7} & \multicolumn{2}{|c|}{100} & \multicolumn{2}{|r|}{100} & 100 \\
\hline Ceftazidime & \multicolumn{2}{|r|}{ ND } & \multicolumn{2}{|r|}{ ND } & \multicolumn{2}{|c|}{44.4} & \multicolumn{2}{|c|}{ Not Done } & Not Done \\
\hline Cefepime & & 75 & & 100 & & $\mathrm{D}$ & & 100 & 66.7 \\
\hline Meropenem & & 27.8 & & 29.2 & & & & 16.67 & - \\
\hline Tigecycline & & 12.5 & & 18.7 & No & Done & & - & - \\
\hline Co-Trimoxazole & & 85.7 & & 92.8 & & & & 100 & 50 \\
\hline Doxycycline & & 62.5 & & 50 & No & Done & & 25 & 33.33 \\
\hline Gentamicin & & 80 & & 93.33 & & & & 75 & 50 \\
\hline Amikacin & & 75 & & 92.85 & & & & 60 & 25 \\
\hline Ciprofloxacin & & 88.9 & & 75 & & & & 80 & 33.33 \\
\hline Polymyxin B & & 11.8 & & - & & & & - & - \\
\hline Table-III: Freque & & elative frequency & id rel & tive risk of $\mathrm{cc}$ & morbid a & ociated. & & & \\
\hline Disease & & \begin{tabular}{l|r} 
& Freq \\
\end{tabular} & ency & & Relative F & quency (1 & 136) & & Relative Risk \\
\hline Diabetes & & & 88 & & & 0.65 & & & 2.16 \\
\hline Hypertension & & & 15 & & & 0.84 & & & 1.37 \\
\hline Cardiovascular Di & ase & & 41 & & & 0.30 & & & 1.31 \\
\hline Autoimmune Dise & & & 39 & & & .28 & & & 1.72 \\
\hline Liver Disease & & & 23 & & & 0.16 & & & 1.15 \\
\hline Misc & & & 53 & & & 0.39 & & & 1.03 \\
\hline Table-IV: Rates o & & with common orga & nisms & n similar stu & dies. & & & & \\
\hline Data & & $\begin{array}{l}\text { Incidence of B } \\
\text { (per } 1000 \text { patient }\end{array}$ & $\begin{array}{l}\text { I } \\
\text { ays) }\end{array}$ & $\begin{array}{r}\text { 1st Comn } \\
\text { Organ } \\
\end{array}$ & $\begin{array}{l}\text { nonest } \\
\text { ism }\end{array}$ & $\begin{array}{r}\text { 2nd C } \\
\text { Or }\end{array}$ & $\begin{array}{l}\text { nmol } \\
\text { inism }\end{array}$ & & $\begin{array}{c}\text { 3rd Commonest } \\
\text { Organism }\end{array}$ \\
\hline Our Data & & 5.48 & & $\begin{array}{r}\text { Coagulase } \\
\text { Staphylc } \\
\end{array}$ & $\begin{array}{l}\text { negative } \\
\text { cocci }\end{array}$ & $\begin{array}{r}\text { Staph } \\
\mathrm{a}\end{array}$ & $\begin{array}{l}\text { lococ } \\
\text { ceus }\end{array}$ & cus & $\begin{array}{c}\text { Klebsiella } \\
\text { pneumoniae }\end{array}$ \\
\hline Zhang et al, 201914 & & 0.84 & & $\begin{array}{r}\text { Staphylo } \\
\text { aure }\end{array}$ & $\begin{array}{l}\text { coccus } \\
\text { us }\end{array}$ & Enterc & acter & spp & $\begin{array}{c}\text { Coagulase negative } \\
\text { Staphylococci }\end{array}$ \\
\hline Sahli et al, $2017^{15}$ & & 10.8 & & $\begin{array}{r}\text { Klebsi } \\
\text { pneums }\end{array}$ & ella & $\begin{array}{r}\text { Coagul } \\
\text { Stap }\end{array}$ & $\begin{array}{l}\text { e neg } \\
\text { loco }\end{array}$ & $\begin{array}{l}\text { ative } \\
\text { cci }\end{array}$ & $\begin{array}{c}\text { Staphylococcus } \\
\text { aureus }\end{array}$ \\
\hline $\begin{array}{l}\text { Menegueti et al, } \\
201716\end{array}$ & & 6.1 & & $\begin{array}{r}\text { Coagulase } \\
\text { Staphyl }\end{array}$ & $\begin{array}{l}\text { negative } \\
\text { cocci }\end{array}$ & $\begin{array}{r}\text { Staph } \\
\mathrm{a}\end{array}$ & $\begin{array}{l}\text { lococ } \\
\text { ceus }\end{array}$ & cus & $\begin{array}{c}\text { Pseudomonas } \\
\text { aeruginosa }\end{array}$ \\
\hline Chandra et al, 201 & & ND & & $\begin{array}{r}\text { Coagulase } \\
\text { Staphyl }\end{array}$ & $\begin{array}{l}\text { negative } \\
\text { cocci }\end{array}$ & $\begin{array}{r}\text { Staph } \\
\mathrm{a}\end{array}$ & $\begin{array}{l}\text { lococ } \\
\text { ceus }\end{array}$ & & $\begin{array}{l}\text { Acinetobacter } \\
\text { baumanii }\end{array}$ \\
\hline Fysaraki et al, 2013 & & 3.18 & & $\begin{array}{r}\text { Staphylo } \\
\text { aure }\end{array}$ & $\begin{array}{l}\text { coccus } \\
\text { us }\end{array}$ & $\begin{array}{r}\text { Coagul } \\
\text { Stap }\end{array}$ & $\begin{array}{l}\text { e neg } \\
\text { floco }\end{array}$ & $\begin{array}{l}\text { ative } \\
\text { cci }\end{array}$ & Escherichia coli \\
\hline
\end{tabular}

were also found to be similar across the board with Gram-positive organisms in 2 of top 3 positions in almost all similar studies.

Studies have reported fever with chills to be most common symptom associated with CRBSI which was seen in about $65 \%$ of our patients $3,9,18,19$. It has high sen- gulase-negative Staphylococci, $58.6 \%$ of $S$. aureus and $83.3 \%$ of Staphylococcus haemolyticus isolates were found to be methicillin (cloxacillin) resistant. However, all gram-positive organisms were found to be sensitive to vancomycin and tigecycline. doxycycline sensitivity was also surprisingly high at $93.24 \%$ across all Gram- 
positive organisms which has not been demonstrated in similar studies like Pandit et al22, and Gafor et al23. Gram negative infections were found to have polymicrobial resistance. Antibiotics with relatively high sensitivity $(>50 \%)$ in descending order were Polymyxin B, Tigecycline, Meropenem and Piperacillin-Tazobactam (Pip-Tazo). Among 47.2\% of gram-negative isolates were susceptible to doxycycline. High degree of penicillin, cephalosporin, quinolone and aminoglycoside resistance were noted in these isolates. Based on above data empiric therapy for all severe CRBSI patients must include vancomycin for gram-positive coverage and either a carbapenem or Pip-Tazo for gram negative coverage.

Another highlighted aspect in this study was high rates of CRBSI secondary to femoral vein catheterization as compared to IJV catheterization. Femoral catheters were used for temporary access in patients undergoing emergency hemodialysis or those awaiting definite procedures for permanent access. Oliver et al24, reports high rates of bacteremia secondary to femoral catheters 27 with relative risk of 3.1 vs 2.36 in this study. Therefore, IJV catheterization should be preferred over femoral.

As this study was only observational in nature, we did not compare use of described antimicrobial drug in these patients, which can be subject of future study in our population.

\section{CONCLUSION}

More than $80 \%$ of CKD patients require hemodialysis via non-tunneled catheter at least once ${ }^{2}$. Although necessary, this intervention puts patient at risk of CRBSI which has a mortality rate of up to $25 \%$ in patients undergoing hemodialysis. Early control of CRBSI requires knowledge of effective empirical therapy which further requires knowledge of local antibio-gram. This study has highlighted antibiogram in this selected population. Gram positive organisms were seen more commonly which were fully susceptible to Vancomycin. Gram negative organisms, on the other hand were relatively more resistant and no single antimicrobial was found to be $100 \%$ effective. However, on this data, empiric therapy in these infections should include vancomycin with either a carbapenem or piperacillin-tazobactam. Furthermore, IJV catheters due to low infection rates should be preferred to reduce chances of CRBSI.

\section{CONFLICT OF INTEREST}

This study has no conflict of interest to be declared by any author.

\section{REFERENCES}

1. Bond A, Chadwick P, Smith T, Nightingale J, Lal S. Diagnosis and management of catheter-related bloodstream infections in patients on home parenteral nutrition. Frontline Gastroenterol 2019; 11(1): 48-54.

2. Saran R, Robinson B, Abbott K, Bragg-Gresham J, Shahinian V, Ayanian J, et al. US Renal Data System 2019 Annual Data Report: Epidemiology of Kidney Disease in the United States. Am J Kidney Dis 2020; 75(1): A6-A7.

3. Allon M. Dialysis catheter-related bacteremia: Treatment and prophylaxis. Am J Kidney Dis 2004; 44(5): 779-91.

4. Farrington C, Allon M. Complications of Hemodialysis Catheter Bloodstream Infections: Impact of Infecting Organism. Am J Nephrol 2019; 50(2): 126-32..

5. Qureshi AL, Abid K. Frequency of Catheter Related Infections in Hemodialyzed Uremic Patients. J Pak Med Assoc 2010; 60(8): $671-75$.

6. Katneni R, Hedayati S. Central venous catheter-related bacteremia in chronic hemodialysis patients: epidemiology and evidence-based management. Nat Rev Nephro 2007; 3(5): 256-66.

7. O'Seaghdha CM, Foley RN. Septicemia, access, cardiovascular disease, and death in dialysis patients. Perit Dial Int 2005; 25(6): $534-40$.

8. Wasse H. Reducing tunneled hemodialysis catheter morbidity: catheter-related mortality among ESRD patients. Semin Dial 2008; 21(6): 547-49.

9. Nassar G, Ayus J. Infectious complications of the hemodialysis access. Kidney Int 2001; 60(1): 1-13.

10. Towns M, Jarvis W, Hsueh P. Guidelines on Blood Cultures. J Microbiol Immunol Infect 2010; 43(4): 347-49.

11. Mermel LA, Allon M, Bouza E, Craven DE, Flynn P, O'Grady $\mathrm{NP}$, et al. Clinical practice guidelines for the diagnosis and management of intravascular catheter-related infection: 2009. Update by the Infectious Diseases Society of America. Clin Infect Dis 2009; 49(1): 1e-45.

12. Ramanathan V, Chiu E, Thomas J, Khan A, Dolson G, Darouiche $R$. Healthcare costs associated with hemodialysis catheter-related infections: a single-center experience. Infect Control Hosp Epidemiol 2007; 28(5): 606-609.

13. Rosenthal V. International Nosocomial Infection Control Consortium (INICC) resources: INICC multidimensional approach and INICC surveillance online system. Am J Infect Control 2016; 44(6): e81-e90.

14. Zhang H, Cortés-Penfield N, Mandayam S, Niu J, Atmar R, Wu E, et al. Dialysis Catheter-related bloodstream infections in patients receiving hemodialysis on an emergency-only basis: a retrospective cohort analysis. Clin Infect Dis 2018; 68(6): 1011-16.

15. Sahli F, Feidjel R, Laalaoui R. Hemodialysis catheter-related infection: rates, risk factors and pathogens. J Infect Public Heal 2017; 10(4): 403-408.

16. Menegueti M, Betoni N, Bellissimo-Rodrigues F. Central venous catheter-related infections in patients receiving short-term hemodialysis therapy: incidence, associated factors, and microbiological aspects. Rev Soc Bras Med Trop 2017; 50(6): 783-87.

17. Chandra A, Das A, Sen M, Srivastava D. Haemodialysis catheterrelated blood stream infection in ESRD patients: incidence, outcome and antibiogram of the isolated organisms. J Adv Med Med Res 2016; 1(1): 912-19.

18. Fysaraki M, Samonis G, Valachis A, Daphnis E, Karageorgopoulos D, Falagas M, et al. Incidence, clinical, microbiological features and outcome of bloodstream infections in patients undergoing hemodialysis. Int J Med Sci Public Health 2013; 10(12): 1632-38. 
19. Thompson S, Wiebe N, Klarenbach S, Pelletier R, Hemmelgarn B, Gill J, et al. Catheter-related blood stream infections in hemodialysis patients: a prospective cohort study. BMC Nephrol 2017; 18(1): 357-62.

20. O'Grady N, Barie P, Bartlett J, Bleck T, Carroll K, Kalil A, et al. Guidelines for evaluation of new fever in critically ill adult patients: 2008 update from the American College of Critical Care Medicine and the Infectious Diseases Society of America. Crit Care Med 2008; 36(4): 1330-49.

21. Fletcher S. Catheter-related bloodstream infection. Continuing Educat Anaesth Critical Care Pain 2005; 5(2): 49-51.
22. Pandit P, Sahni A, Grover N, Dudhat V, Das N, Biswas A. catheter-related blood stream infections: prevalence, risk factors and antimicrobial resistance pattern. Med J Armed For Ind 2021; 77(1): 38-45.

23. Abdul Gafor A, Cheong Ping P, Zainal Abidin A, Saruddin M, Kah Yan N, Adam S. Antibiogram for haemodialysis catheterrelated bloodstream infections. Int J Nephrol 2015; 2014(1): 1-6.

24. Oliver M, Callery S, Thorpe K, Schwab S, Churchill D. Risk of bacteremia from temporary hemodialysis catheters by site of insertion and duration of use: A prospective study. Kidney Int 2000; 58(6): 2543-45. 